\title{
A Survey on the Willingness of Clinical Research Professionals to Participate in Clinical Research
}

Rania M. Felemban ${ }^{1 *}$, Soha Elmorsy ${ }^{1}$, Matthew D. Dick ${ }^{2}$ and Irwin Martin ${ }^{3}$

${ }^{1}$ King Abdullah Medical City, Makkah al Mukarramah, Saudi Arabia

${ }^{2}$ Counseling Department, Eastern Michigan University, United States of America

${ }^{3}$ School of Health Sciences, Eastern Michigan University, United States of America

\begin{abstract}
Objective: To identify the impact of professional knowledge and education on willingness to participate in clinical trials.

Methods: The study was conducted during January 2017 at Eastern Michigan University, Michigan, United States. It was a cross-sectional quantitative study in which clinical research professionals were invited to complete a shortened version of the Center for Information and Study on Clinical Research Participation (CISCRP) survey assessing their willingness to participate in clinical trials. A comparison was made between the sample of this study and the results of the CISCRP survey.
\end{abstract}

Results: The 83 people who answered the survey represent $20 \%$ of the total number of people, which are 415 , who were invited to participate. The study found that $80.6 \%$ of the survey respondents were willing to participate in clinical trials, significantly less than the results of the CISCRP survey on postgraduates, which found that $96.3 \%$ of respondents were willing to participate in clinical trials. In the present study, willingness was significantly higher among females and those with previous clinical trials experience. Willingness to participate correlated positively with perception of clinical trials safety $(r=0.503, p<0.001)$.

Conclusion: Overall, the clinical research professionals were moderately willing to participate in clinical trials but they were less willing to participate in clinical trials than the postgraduate participants of the CISCRP survey. Although some factors such as safety and type of medical intervention must be considered when attempting actual participation, knowledge and professional background affected the willingness to participate in clinical trials. These findings should not discourage efforts to recruit clinical research professionals into clinical trials.

Keywords: Clinical research professional; Willingness to participate; Inclined to participate; Clinical research safety; Clinical research risks; Clinical research benefits

\section{Introduction}

A large proportion of research on potential participants in clinical trials of clinical research professionals remains incomplete. Populations' recruitment has targeted typical and more traditional patient. However, clinical research professionals and the postgraduate public with clinical knowledge represent a considerable population still to be studied. Knowledge of clinical research professionals' willingness to participate in clinical trials might enhance the diversity and effectiveness of recruitment. Willing and unwilling groups have different characteristics. According to a quantitative research of Teschke et al. [1] on the public opinions about participating in clinical research, the characteristics of willing participants include having a sick family member, being elderly, having had prior involvement in clinical research, or having a positive inclination toward clinical trials participation. Knowing research results were also a great motivator to participate in clinical trials. The characteristics of unwilling respondents included having a postgraduate education or professional knowledge and an attitude to participate in clinical trials depending on the objective of the trial [1]. Therefore, the characteristics of willing and unwilling participants in clinical trials vary based on the participants' perspectives in clinical trials

There is a lack of knowledge about the willingness of clinical research professionals to participate in clinical trials. The objectives of this study were to assess this willingness among clinical research professionals, to try to explore the determinants of willingness, and to identify the impact of professional clinical research knowledge on the willingness to participate in clinical trials by comparing results of clinical research professionals to those obtained in surveys of other educated populations. For such a comparison, the aggregated data of the postgraduate education subgroup in the survey performed by the Center for Information and Study on Clinical Research Participation (CISCRP) [2] were used. The assumption was that there would be no statistically significant' difference in the distribution of responses concerning willingness to participate between clinical research professionals and public postgraduate participants.

\section{Research Design and Methodology}

\section{Research subjects}

Potential research participants were alumni graduated in years 2000 to 2015 of the Clinical Research Administration (CRA) graduate program at Eastern Michigan University. Students who had not yet graduated from the CRA graduate program were excluded.

*Corresponding author: Rania M Felemban, MSc, King Abdullah Medical City, Makkah al Mukarramah, Saudi Arabia; E-mail: raniafelemban@gmail.com

Received June 24, 2017; Accepted October 20, 2017; Published October 27, 2017

Citation: Felemban RM, Elmorsy S, Dick MD, Martin IG (2017) A Survey on the Willingness of Clinical Research Professionals to Participate in Clinical Research J AIDS Clin Res 8: 739. doi: 10.4172/2155-6113.1000739

Copyright: (C) 2017 Felemban RM, et al. This is an open-access article distributed under the terms of the Creative Commons Attribution License, which permits unrestricted use, distribution, and reproduction in any medium, provided the original author and source are credited. 


\section{Research methods}

Clinical research administration graduate program data: A cross-sectional quantitative study was performed using a purposive sample of 419 clinical research professionals, whose details were derived from the database of the CRA department of Eastern Michigan University. The study was approved by the University Human Subjects Review Committee (UHSRC) and was conducted in January 2017.

Participants were invited by email to participate in an anonymous online survey. The introductory page of the survey covered the participation consent information and the voluntary nature of the survey. The first part of the survey queried demographic data such as residency, age, race, gender, employment status, occupation, and income. The second part of the survey assessed willingness to participate in clinical trials. It involved a question about willingness to participate in clinical trials as a research subject, to which there were five response options: "not at all willing," "not very willing," "somewhat willing," "very willing," and "not sure." Another two questions were posed regarding their efforts to join clinical trials and actual participation. These were direct yes or no questions. Other detailed questions examined the reasons that might make them want to participate in clinical trials, and how they perceived clinical research safety. Participants were then required to evaluate their level of agreement with various statements. A further question determined the participants' perception of the level of safety of clinical trials by asking them to select one of the following: "very safe," "somewhat safe," "not very safe" or "not at all safe." Finally, participants were asked to specify possible benefits and risks of participating in clinical trials.

CISCRP database: The CISCRP, an independent nonprofit organization, conducted an international online validated survey in 2015, titled "The 2015 CISCRP Perceptions and Insights Study: Report on General Perceptions". The study presents valuable and substantive insights into actionable ways that clinical trials stakeholders can better comprehend and more adequately engage with the general population and study participants.

More than 12,000 people responded to the CISCRP survey, including 560 postgraduate (i.e., holding masters or doctorate-level degrees) US residents. The aggregated data of this subgroup was obtained from CISCRP and compared to the data of the CRA study, with a focus on willingness to participate in clinical trials.

\section{Data management}

Data were collected via Survey Monkey and statistical analyses were conducted using IBM SPSS Statistics 24. Categorical data were presented as percentages and data relating to willingness, safety perceptions, and agreement with statements were collected using a Likert scale (1-5). The Likert-scale data were presented as median values and quantiles and were compared between subgroups of participants using non-parametric tests (Mann Whitney and Kruskal Wallis tests as appropriate). Spearman Rank Correlation was used to test the relation between responses to different statements and willingness to participate and perception of safety. A chi square goodness-of-fit test was used to compare results from the CRA graduate and the CISCRP postgraduate sample data. All alpha values were two-sided and were set at 0.05 .

\section{Results}

Table 1 displays the characteristics of the clinical research professionals who participated in the study. The total number of respondents was 83 , representing approximately $20 \%$ of the total number invited to participate in the survey. The number of females in the sample was 25 compared with 58 males. Those between 30 and 40 years old constituted the largest age category. Most of the participants were fully employed with an annual gross income of over $\$ 75,000$. Those who had previously tried to participate in clinical trials were fewer than those who had not. Similarly, the percentage of those who had actually participated in clinical trials was fewer than those who had not. Some percentage does not sum up to $100 \%$ because of non-responders.

Table 2 shows the perception of safety and willingness to participate in clinical trials among CRA graduates. Although females and males did not differ significantly in their perception of safety $(p=0.439)$, females appear to be significantly more willing to participate in clinical trials $(p=0.008)$. There were no significant differences among age groups regarding perception of safety or willingness to participate $(p>0.05)$. Neither was there a difference between those employed full-time or part-time. Gross income did not appear to significantly influence willingness to participate despite there being differences in perception of safety. Those who had previously tried to participate and those who had actually participated in clinical trials were significantly more willing to participate in clinical trials and had a higher perception of safety $(p<0.05)$.

A Spearman's correlation analysis (Table 3) revealed a moderately positive but significant correlation between perception of safety and willingness to participate in clinical trials $(r=0.503, p<0.001)$. All other correlation effect sizes were generally weak but some were statistically significant. Examples of features that were significantly and positively correlated with safety and willingness to participate include: having a terminal illness, knowing the risks associated with the treatment, believing the treatment would help in the future, and finding the time commitment reasonable $(p<0.05)$. Examples of features that were significantly positively correlated with willingness to participate but were not significantly correlated with safety include: having incentives for participating, having a free treatment, and knowing that the treatment offered in the trial is the only medical option $(p<0.05)$.

Table 4 displays a comparison of the willingness to participate in clinical trials between the CRA graduate and the CISCRP postgraduate sample data. Chi square goodness-of-fit tests revealed a significant difference in the distribution of responses relating to participants willingness to participate in clinical research $(\mathrm{p}<0.001)$. More than $96 \%$

\begin{tabular}{|l|l|l|}
\hline \multicolumn{1}{|c|}{ Group } & Characteristics & N (\%) \\
\hline Total & & $83(100)$ \\
\hline Gender & Male & $25(30.1)$ \\
\hline \multirow{2}{*}{ Age } & Female & $58(69.9)$ \\
\hline \multirow{5}{*}{ Employment } & $<30$ & $23(27.7)$ \\
\hline \multirow{2}{*}{ Income } & $30-40$ & $31(37.3)$ \\
\hline \multirow{2}{*}{ Previously tried to participate in clinical trials } & $40-50$ & $13(15.7)$ \\
\hline & $>50$ & $14(16.9)$ \\
\hline Previously participated in clinical trials & No & $69(83.1)$ \\
\hline & Yes & $5(6.0)$ \\
\hline & Part-time & $28(33.7)$ \\
\hline & $<75,000$ & $42(50.6)$ \\
\hline & No & $53(63.9)$ \\
\hline & Yes & $25(30.1)$ \\
\hline
\end{tabular}

Table 1: Characteristics of CRA graduates participating in the study. 


\begin{tabular}{|c|c|c|c|c|c|c|c|c|c|}
\hline \multicolumn{2}{|l|}{ Group } & \multicolumn{4}{|c|}{ Perception of clinical trial safety } & \multicolumn{4}{|c|}{ Willingness to participate in clinical trials } \\
\hline & & $\begin{array}{c}\text { Median (Quan- } \\
\text { tiles) }\end{array}$ & Mean rank & $p$ value & $\begin{array}{c}\text { Those considering } \\
\text { clinical trials safe } \\
\text { or somewhat safe } \\
{[N(\%)]}\end{array}$ & $\begin{array}{c}\text { Median } \\
\text { (Quantiles) }\end{array}$ & Mean rank & $p$ value & $\begin{array}{c}\text { Those willing or } \\
\text { somewhat willing } \\
\text { to participate } \\
{[N(\%)]}\end{array}$ \\
\hline \multirow[t]{2}{*}{ Gender } & Male & $3(3-4)$ & 37.85 & \multirow[t]{2}{*}{.439} & $8(33.3)$ & $4(2-4)$ & 30.10 & \multirow[t]{2}{*}{$0.008^{*}$} & $16(66.7)$ \\
\hline & Female & $3(3-4)$ & 41.63 & & $20(35.7)$ & $4(4-5)$ & 43.68 & & $47(87.0)$ \\
\hline \multirow[t]{4}{*}{ Age } & $<30$ & $3(3-3)$ & 33.07 & \multirow[t]{4}{*}{0.184} & $4(18.2)$ & $3(3-4)$ & 30.71 & \multirow[t]{4}{*}{0.081} & $15(71.4)$ \\
\hline & $30-40$ & $3(3-4)$ & 39.05 & & $10(33.3)$ & $4(4-5)$ & 38.95 & & $24(82.8)$ \\
\hline & $40-50$ & $3(3-4)$ & 44.58 & & $6(46.2)$ & $4(4-5)$ & 39.50 & & $12(92.3)$ \\
\hline & $>50$ & $3(3-4)$ & 46.35 & & $8(61.5)$ & $4(4-5)$ & 49.08 & & $11(84.6)$ \\
\hline \multirow[t]{2}{*}{ Employment } & Full-time & $3(3-4)$ & 40.18 & \multirow[t]{2}{*}{0.947} & $23(34.8)$ & $4(4-5)$ & 38.82 & \multirow[t]{2}{*}{0.536} & $50(67.1)$ \\
\hline & Part-time & $3(3-4)$ & 40.57 & & $5(35.7)$ & $4(4-5)$ & 42.61 & & $13(92.9)$ \\
\hline \multirow[t]{2}{*}{ Income } & $<75,000$ & $3(3-3)$ & 27.45 & \multirow[t]{2}{*}{$0.004^{*}$} & $5(17.9)$ & $4(4-4)$ & 29.68 & \multirow[t]{2}{*}{0.130} & $22(78.6)$ \\
\hline & $\geq 75,000$ & $3(3-4)$ & 39.44 & & $19(47.5)$ & $4(4-5)$ & 36.32 & & $32(84.2)$ \\
\hline \multirow{2}{*}{$\begin{array}{l}\text { Previously tried to partici- } \\
\text { pate in clinical trials }\end{array}$} & No & $3(3-3)$ & 35.13 & \multirow[t]{2}{*}{$0.004^{*}$} & $13(24.5)$ & $3(3-4)$ & 33.67 & \multirow[t]{2}{*}{$<0.001^{*}$} & 39 (73.6) \\
\hline & Yes & $3(3-4)$ & 48.76 & & $15(60.0)$ & $4(4-5)$ & 51.86 & & $24(96.0)$ \\
\hline \multirow{2}{*}{$\begin{array}{l}\text { Previously participated in } \\
\text { clinical trials }\end{array}$} & No & $3(3-4)$ & 34.83 & \multirow[t]{2}{*}{$0.001^{*}$} & $14(24.6)$ & $4(3-4)$ & 34.35 & \multirow[t]{2}{*}{$<0.001^{*}$} & $43(75.4)$ \\
\hline & Yes & $4(3-4)$ & 52.17 & & $14(66.7)$ & $5(4-5)$ & 53.48 & & $20(95.2)$ \\
\hline
\end{tabular}

Note: ${ }^{*} p<0.05,{ }^{* *} p<0.01,{ }^{* * *} p<0.001$

Table 2: Perception of safety and willingness to participate in clinical trials among CRA graduates participating in the study.

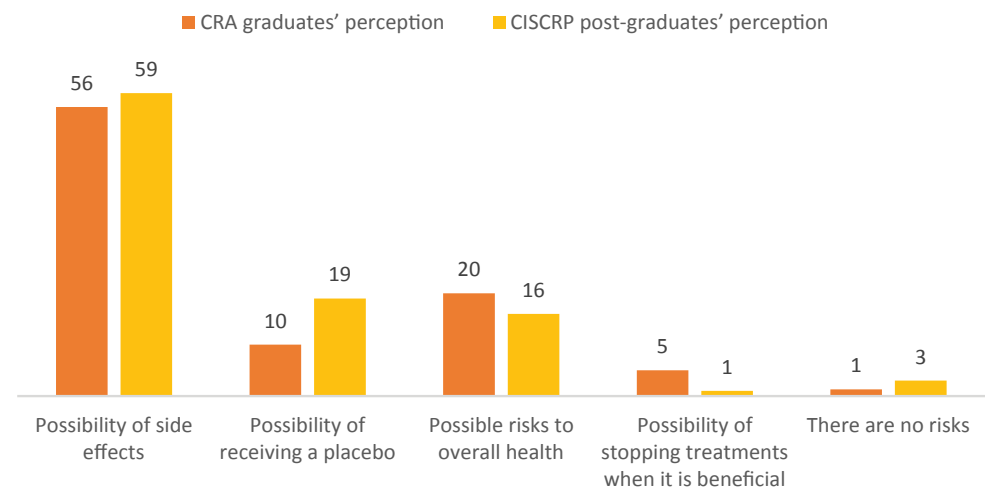

Figure 1: Comparison of perceptions of the greatest risk associated with clinical trials among CRA and CISCRP study participants (\% of study participants giving each response).

of the CISCRP samples were at least somewhat willing to participate as compared to only $80 \%$ of the CRA clinical research professionals sample.

Figure 1 shows a comparison of perceived great risks of clinical trials between CRA graduate participants and the CISCRP postgraduate sample. By far, the possibility of side effects was the greatest risk perceived in both samples, with $56 \%$ and $59 \%$ of study participants giving this response in the two studies, respectively. Generally, the distribution of perceived risks was similar in both samples except for the possibility of receiving a placebo, which was more often perceived as the greatest risk among the CISCRP participants than among the CRA participants, with values of $19 \%$ and $10 \%$ respectively.

Figure 2 shows the possible benefits of clinical trials participation as perceived by the CRA participants. Advancing the science was perceived as the greatest benefit, while none of the following were perceived benefits: receiving money for participation, free medication, free medical care, and understanding an inherited disease.

\section{Discussion}

The results of the current study show a reasonably high willingness (around 80\%) of clinical research professionals to participate in clinical trials, yet this willingness was substantially lower than that indicated (96\%) in the postgraduate subgroup of the CISCRP survey [2]. According to CISCRP survey, approximately $80 \%$ of the general population had a positive preference to be involved in clinical trials. Although there was a significant difference between the clinical research professionals and postgraduate subgroup of the CISCRP, it was difficult to generalize this result to all clinical research professionals because of the low response rate. However, these findings were similar as those of Fayed, who distributed a survey about willingness to participate in clinical trials to a group of medical and nursing students, physicians, and nurses. Around $90 \%$ of Fayed's [3] sample responded that they were willing to participate in clinical trials. These results were similar to those of Bouida et al. [4], in which $89 \%$ of physicians responded that they were willing to participate in clinical trials. Apart from the level of willingness of professionals to participate in clinical trials, the level of education and knowledge is another factor that distinguishes the public from professionals.

Regarding the determinants of willingness to participate in clinical trials, the current study found that those with previous experience of clinical trials were more willing. Those having a terminal illness and 
Citation: Felemban RM, Elmorsy S, Dick MD, Martin IG (2017) A Survey on the Willingness of Clinical Research Professionals to Participate in Clinical Research. J AIDS Clin Res 8: 739. doi: 10.4172/2155-6113.1000739

Page 4 of 6

\begin{tabular}{|c|c|c|c|c|}
\hline \multirow{2}{*}{ Variables } & \multicolumn{2}{|c|}{ Perception of clinical trial safety } & \multicolumn{2}{|c|}{ Willingness to participate in clinical trials } \\
\hline & $r$ & $p$ & $r$ & $p$ \\
\hline Willing to participate in clinical trials & 0.503 & $.000^{* \star *}$ & & \\
\hline Access to best doctors & 0.089 & 0.436 & -0.082 & 0.475 \\
\hline Get the best possible treatment & 0.298 & $0.008^{* *}$ & 0.133 & 0.247 \\
\hline Being an experimental test subject rather than being a patient & -0.291 & $0.009^{* *}$ & -0.261 & $0.021^{*}$ \\
\hline Contributing to science & 0.209 & 0.065 & 0.296 & $0.009^{* *}$ \\
\hline Receiving free medicine and care & -0.095 & 0.407 & 0.055 & 0.631 \\
\hline Health gambling & -0.416 & $.000^{* *}$ & -0.179 & -0.179 \\
\hline Learning more about my health condition & 0.167 & 0.145 & 0.182 & 0.182 \\
\hline Time spent at the doctor's office & 0.008 & 0.947 & 0.272 & 0.272 \\
\hline Receiving more time and attention from medical experts & 0.137 & 0.233 & 0.146 & 0.146 \\
\hline Potential risks and benefits & 0.105 & 0.362 & 0.109 & 0.109 \\
\hline Physical location of the research center & 0.109 & 0.344 & -0.062 & -0.062 \\
\hline Time commitment & -0.087 & 0.448 & -0.185 & -0.185 \\
\hline Types of medical procedures required & -0.054 & 0.638 & -0.051 & -0.051 \\
\hline Purpose of the clinical research study & 0.032 & 0.784 & 0.101 & 0.101 \\
\hline Having access to the study drug after the trial & 0.048 & 0.679 & 0.014 & 0.014 \\
\hline Confidentiality is protected & -0.158 & 0.171 & -0.206 & -0.206 \\
\hline Receiving the study results after the trial ends & -0.038 & 0.738 & -0.222 & -0.222 \\
\hline Potential costs and reimbursements & 0.069 & 0.549 & -0.055 & -0.055 \\
\hline Experiences of previous research participants & -0.068 & 0.553 & -0.045 & -0.045 \\
\hline If I had a terminal illness & 0.261 & $0.021^{*}$ & 0.274 & $0.015^{*}$ \\
\hline If I thought a study drug might cure me & 0.171 & 0.138 & $0.271^{*}$ & 0.017 \\
\hline If I knew that I would receive an active drug and not a placebo & 0.026 & 0.820 & 0.219 & 0.056 \\
\hline If I received money for participating & 0.132 & 0.251 & 0.301 & $0.008^{* *}$ \\
\hline If I knew the risks associated with the treatment & 0.260 & $0.023^{*}$ & 0.248 & $0.030^{*}$ \\
\hline If I knew that it would not cost me anything to participate & 0.255 & $0.026^{*}$ & 0.390 & $0.000^{* *}$ \\
\hline If I knew there were no risks involved & 0.094 & 0.416 & 0.138 & 0.232 \\
\hline If my doctor recommended it & 0.074 & 0.524 & 0.200 & 0.080 \\
\hline If the treatment were free of charge to me & 0.198 & 0.085 & 0.303 & $0.007^{* *}$ \\
\hline If I thought the treatment would help me & 0.146 & 0.206 & 0.255 & $0.025^{*}$ \\
\hline If it were convenient for me to participate & 0.335 & $0.003^{* *}$ & 0.245 & $0.032^{*}$ \\
\hline If I had a condition other than a terminal illness & 0.243 & $0.033^{*}$ & 0.316 & $0.005^{\star *}$ \\
\hline If there were no other medical options available to me & 0.221 & 0.055 & 0.254 & $0.027^{*}$ \\
\hline If there were minimal side effects associated with the treatment & 0.210 & 0.071 & 0.226 & 0.051 \\
\hline If I thought the treatment would help someone else in the future & 0.311 & $0.006^{* *}$ & 0.327 & $0.004^{* *}$ \\
\hline If I knew someone else with my condition was participating in the study & 0.148 & 0.198 & 0.173 & 0.132 \\
\hline If my family recommended it & 0.020 & 0.861 & 0.070 & 0.545 \\
\hline If it were recommended via an online social network or disease forum & 0.033 & 0.774 & 0.288 & $0.011^{*}$ \\
\hline If the time commitment was reasonable & 0.356 & $0.002^{* *}$ & 0.428 & $0.000^{* *}$ \\
\hline If a summary of the research results would be shared & 0.159 & 0.166 & 0.073 & 0.531 \\
\hline
\end{tabular}

Note: ${ }^{*} p<0.05,{ }^{* *} p<0.01,{ }^{* * *} p<0.001$

Table 3: Spearman's correlation analysis results.

knowing the risks associated with the treatment were also more willing to participate. To our knowledge, no previous study has explored the determinants of participation of clinical research professionals in clinical trials. However, the study of Teschke et al. [1] on the public showed that some of the features of willing participants included having a sick family member, being elderly, having had prior involvement in clinical research, or having a positive inclination toward clinical trial participation. Another study [5] described that willingness to participate among patients depended on their disease type and severity. While the study of Sood et al. [6] on attitudes of patients showed that around $68 \%$ of patients were willing to participate in clinical trials, while $82 \%$ of them were unfamiliar with the clinical trials relating to their illness. A further study [7] specified that patients appreciated the contribution

\begin{tabular}{|l|c|c|}
\hline & $\begin{array}{c}\text { CRA graduates' } \\
\text { willingness[N (\%)] }\end{array}$ & $\begin{array}{c}\text { CISCRP postgraduates' } \\
\text { willingness [N (\%)] }\end{array}$ \\
\hline Not sure & $6(7.6)$ & $6(1)$ \\
\hline Not at all willing & $5(6.4)$ & $3(0.5)$ \\
\hline Not very willing & $4(5.1)$ & $11(1.9)$ \\
\hline Somewhat willing & $40(51.2)$ & $229(40.8)$ \\
\hline Very willing & $23(29.4)$ & $311(55.5)$ \\
\hline
\end{tabular}

Table 4: Comparison between CRA graduates and CISCRP postgraduates of willingness to participate in clinical trials.

of clinical trials if these trials were safe and suitable and if they had received adequate information from their physicians. Therefore, having sufficient knowledge about the clinical trials would enhance 


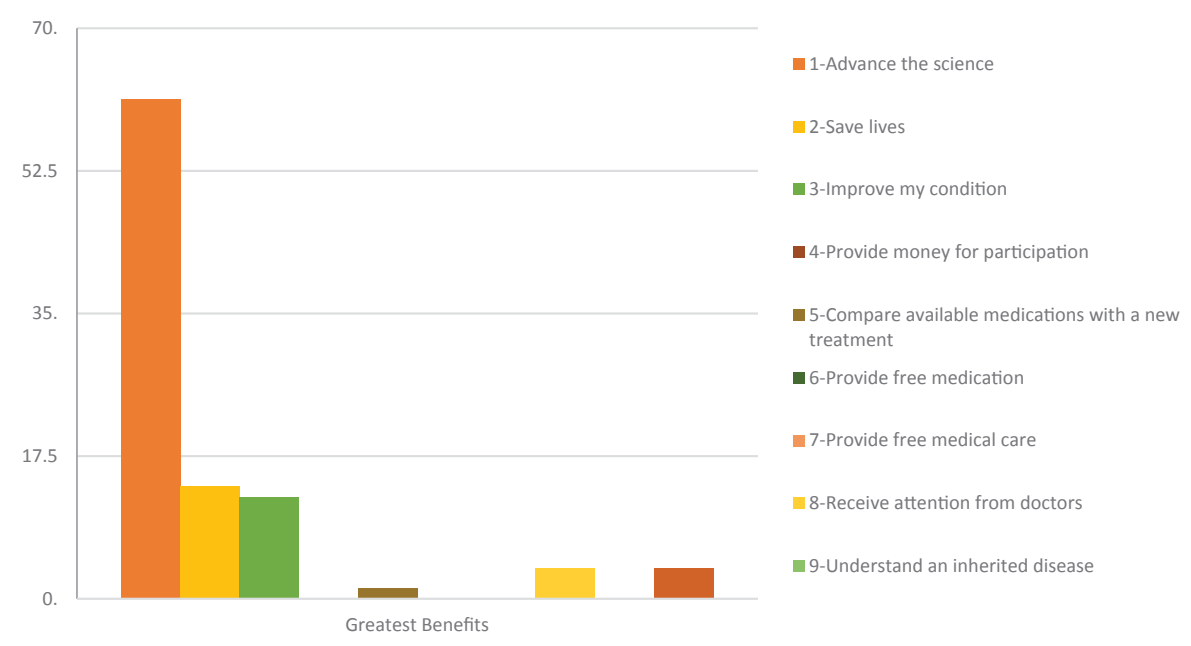

Figure 2: Greatest benefit of participating in clinical trials as perceived by CRA study participants (\% of study participants giving each response).

the willingness to participate. Also, higher willingness among those with previous experience of clinical trials highlights the fact that participation was probably not a bad experience for them.

As for the correlations between willingness and other factors, perception of clinical trials safety was perhaps the most important one. A recent study by Stephanie et al. showed that the type of procedures influence the willingness to participate. Patients who were unwilling to participate due to invasive procedures in trials were more willing to participate when the clinical trials involved less invasive procedures [8]. Therefore, many factors showed correlation with both safety and willingness.

Considering age groups, this study found that the $>50$ years old group were the most willing to participate in clinical trials. This result is consistent with a recent study that found 18-34 year olds were the least willing to participate in clinical trials compared with older generations. This younger generation had health concerns, such as weight control, healthy lifestyle and prevention of diseases that were different than the concerns of the older generations [9]. The perception of willingness to participate in clinical trials of older generation became more predictable.

The percentages of clinical research professional participants and CISCRP post graduates' participants expressing the greatest concern about the side effects of clinical trials were almost equal $56 \%$ and $59 \%$ respectively. In Fayed's study [3], 87.2\% of healthcare provider participants were concerned about adverse events and $79.5 \%$ were concerned about the results of clinical trials. Another study [10] supported the perceived risks of clinical trials participation, which were receiving a placebo, having adverse effects, and exposing to medical intervention. As for how professional knowledge affected the perception of clinical trials risks, the CRA sample were less concerned about receiving a placebo during clinical trial participation than the CISCRP sample.

When considering the benefits of clinical trials participation, advancing the science was the greatest benefit perceived by participants in this study. Results from Teschke et al. [1] showed that possible medical advantages to the person or community encourage participation in clinical trials. However, the CISCRP survey [2] found that only $28 \%$ of the public related their contribution to advancing medical science and developing potential therapies. Compared to this finding for the public, a greater percentage of clinical research professionals and CISCRP postgraduates considered helping advance the science as a benefit.

A strong theme evident in the study is that participation in clinical trials was considered a medical or scientific contribution. First, according to clinical research professionals' responses, the greatest benefit of participating in clinical trials is advancing the science. Second, clinical research professionals' perceptions of how some people feel about clinical trials strongly agreed that clinical trials are considered a scientific contribution. This result suggests that one of the reasons clinical research professionals were less willing to participate in clinical trials is that they are more interested in the field as scientists rather than as clinical research participants.

\section{Research Limitations}

This study surveyed the alumni of the CRA graduate program at Eastern Michigan University, but the respondents might not accurately represent all clinical research professionals due to geographically constrained sample and somewhat low response rate. In addition, the understanding of the nature of clinical trials among this sample of the population may positively or negatively affect their perception of participation in clinical trials.

\section{Conclusion}

Overall, this study found that there was a significant difference between the CRA program graduates and the CISCRP postgraduates in terms of their willingness to participate in clinical trials. The CRA professionals were less willing to participate in clinical trials than the CISCRP postgraduates. Although some factors such as safety and type of medical intervention must be considered when attempting actual participation, knowledge and professional background affected the willingness to participate in clinical trials. These results are understandable, as the studied CRA participants were more knowledgeable about clinical research and had more concerns about their participation. This conclusion should not affect the decision to recruit clinical research professionals in clinical trials. Rather, this work is intended to indicate some of the differences between the two groups. 
Citation: Felemban RM, Elmorsy S, Dick MD, Martin IG (2017) A Survey on the Willingness of Clinical Research Professionals to Participate in Clinical Research. J AIDS Clin Res 8: 739. doi: 10.4172/2155-6113.1000739

Page 6 of 6

\section{Acknowledgement}

Kenneth Getz, MBA, of the Center for Information and Study on Clinical Research Participation (CISCRP), Boston, MA, USA, provided the comparative CISCRP survey data.

\section{References}

1. Teschke K, Marino S, Chu R, Tsui JKC, Harris MA, et al. (2010) Public opinions about participating in health research. Can J Public Health Rev Can Santee Publique 101: 159-164.

2. https://www.ciscrp.org/download/2015-perceptions-insights-study-publicliteracy/?wpdmdl=5738

3. Fayed $A$ (2016) Willingness of a sample of health professionals to participate in clinical research as research subjects. Int J New Technol Res 2: 17-21

4. Bouida W, Grissa MH, Zorgati A, Beltaief $\mathrm{K}$, Boubaker $\mathrm{H}$, et al. (2016) Willingness to participate in health research: Tunisian survey. BMC Med Ethics 17: 47 .

5. English R, Lebovitz Y, Giffin R (2010) Transforming clinical research in the united states: Challenges and opportunities: Workshop summary. National Academies Press, Washington, D.C. 2010.

6. Sood A, Prasad K, Chhatwani L, Shinozaki E, Cha SS, et al. (2009) Patients Attitudes and preferences about participation and recruitment strategies in clinical trials. Mayo Clin Proc 84: 243-247.

7. Agoritsas T, Deom M, Perneger TV (2011) Study design attributes influenced patients' willingness to participate in clinical research: A randomized vignettebased study. J Clin Epidemiol 64: 107-115.

8. Stephanie CC, Ninet S, Gabriella B, Mark AG, Ezekiel E, et al. (2017) Phase 1 healthy volunteer willingness to participate and enrollment preferences. Clin Trials 14: 537-546.

9. Nelson A, Martin I, Getz K (2015) Generational value differences affecting public perceptions of and willingness to participate in clinical trials. Ther Innov Regul Sci 49: 940-946.

10. Brintnall-Karabelas J, Sung S, Cadman ME, Squires C, Whorton K, et al. (2011) Improving recruitment in clinical trials: Why eligible participants decline. J Empir Res Hum Res Ethics 6: 69-74. 